\title{
Odour Assessment for a Pig Farm Through Dynamic Olfactometry and Air Dispersion Modelling in Order to Reduce the Odour Pollution Using Biotechnologies
}

\begin{abstract}
ANDREI VASILE ${ }^{1,2}$, TANASE GHEORGHITA ${ }^{1,2}$, NARCISA BABEANU ${ }^{2}$, OVIDIU POPA $^{2 *}$
${ }^{1}$ National Research and Development Institute for Industrial Ecology ECOIND, 71-73 Drumul Podu Dambovitei Str., 060652, Bucharest, Romania

${ }^{2}$ University of Agronomic Sciences and Veterinary Medicine of Bucharest, Faculty of Biotechnology, 59 Maraşti Blvd 011464, Bucharest, Romania

Odour represents one the most actual topics in terms of industrial pig farming pollution effects, mainly because of the increasing number of settlements build in traditional farming areas but also because of the overpopulation of pigsties. The odour impact assessment was requested by a big pig farm in order to comply to the request of the Environmental Agency to reduce the odour impact on nearby settlements. Odour assessment was done using dynamic olfactometry, mathematical modelling of dispersion and FIDOL factors. The initial assessment was used to elaborate and apply an odour management plan based on biotechnologies which consisted mainly in biological treatments applied to the floor of the pigsties, the slurry transportation channels and the slurry tanks with specific products designed to reduce the Ammonia level, break down her sulphurous compounds in the slurry and increase the quality of the slurry as fertilizer, with the final target of reducing the odour emissions. Results indicate a considerable decrease of odour concentrations in the closest settlements, around the farm and inside pigsties. Further measures must be taken as the concentrations are still over the limit values from most European countries.
\end{abstract}

Keywords: odour, pig farming, slurry, dispersion

Across Romania there are many old pig farms built very close to the villages before the minimum distances where imposed, most of them facing a big number of complaints. Because there is no specific legislation regarding odours, the farms cannot be forced to reduce the odour emissions that are related to many different compounds, such as mercaptans, $\mathrm{H}_{2} \mathrm{~S}, \mathrm{NH}_{3}$ skatole, thiocresol, thiophenol, or other compounds that are involved but were not been identified or reglemented yet (1). These odours have been known to not only cause emotional distress to employees and residents (2), but also pose a potential health risk when odour concentrations are excessive $(3,4)$. It is also important not to neglect the contribution of other pollutants specific to the farm activities like particulate matter from handling of feed and bedding $(5,6)$.

The odour impact assessment was requested by a big pig farm to comply to the request of the Environmental Agency to reduce the odour impact on nearby settlements.

The main objectives of the study were: to assess the impact of the odour emissions on the air quality from settlements in the initial state, to verify the efficiency of the odour management plan that involved the use of biotechnologies in order to reduce the odour emissions and to evaluate the influence of the FIDOL factors.

In odour reduction, many odour control techniques that are being develop erdely on the microbial properties in the swine manure (7).

\section{Experimental part \\ Location}

The farm was built in the communist regime and is continuously operating since then. It is located in a flat agricultural area, with 3 small villages around, which were inhabited in the past manly by the workers of the farm. First village is located at NE - approx. $2000 \mathrm{~m}$ from the farm, the second SW - approx. $1300 \mathrm{~m}$, and the closest at $1100 \mathrm{~m}$.

The farm has 20 pigsties arranged symmetrically on 2 lines, each pigsty with a capacity of 3000 pigs, with a total authorized capacity of 60000 pigs.

Pigs are cyclically introduced in pigsties, they come from breeding farms with an average weight of $25 \mathrm{~kg}$ and head to the slaughter house when they are around $90 \mathrm{~kg}$.

The farm uses the slurry technology. The slurry is collected, transported and then stored in 6 slurry tanks. The slurry is pumped from the bottom so the surface can solidify and act as a cover to reduce the odour emission. The tanks are identical, with a diameter of $50 \mathrm{~m}$, surface area of $2000 \mathrm{~m}^{2}$ and a height of $7 \mathrm{~m}$. The maximum capacity of each tank is

*email: ovid_popa@yahoo.com,Phone: +40 0723693654 
around $12000 \mathrm{~m}^{3}$, but is limited by IEA to $9000 \mathrm{~m} 3$ as a measure related to odour emission. The tanks are regularly emptied and the slurry is spread on agricultural lands according to a specific recipe, manly at the beginning and end of the season. Because the study was done at the beginning of autumn, at the end of the agricultural season, all the tanks were close to the maximum authorized capacity.

The experimental part consisted in: 1) determination of the odour concentrations in pigsties and in the storage tanks on the surface of the slurry; 2) calculation of the emission rate for all sources; 3) processing the emission rate, meteorological and terrain data in order to assess the level of odour pollution in settlements; 4) identifying the isolated impact of the slurry tanks; 5) verifying the efficiency of the odour management plan by repeating all the tests and comparing with the initial results and with odour limits from other European countries; 6) evaluation of the impact of FIDOL factors on the level of nuisance;

Test were made at the end of the summer of 2019.

\section{Odour determination}

Odour concentration was determined according with SR EN 13725:2003, using dynamic olfactometry method, and the olfactometer Odournet T08, developed by Odournet GMBH, Germany. The equipment uses YES/NO method, comply with standard requirements and it is installed in a mobile laboratory accredited to EN ISO/IEC 17025 - Fig.1, to reduce the interval between sampling and analysis. Samples were taken in Nalophan ${ }^{\mathrm{TM}} 10$ odour bags using vacuum sample and analysed in maximum 4 hours from sampling.

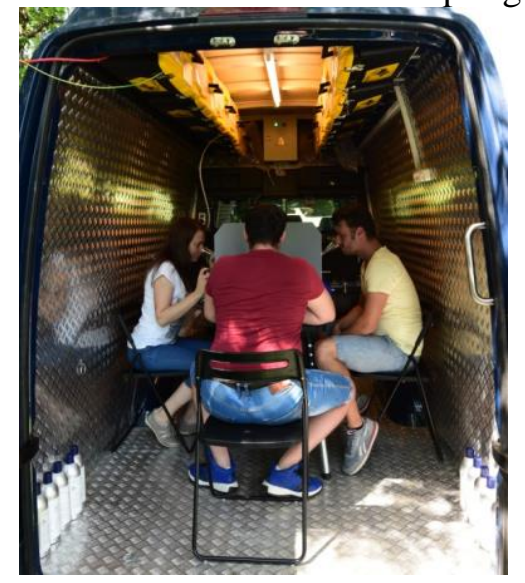

Fig. 1 Odour determination in the mobile olfactometry laboratory

Six validated human assessors have been used, with good sensitivity and repeatability. All assessors where tested with n-butanol before every analysis. Teste were done in a location away from the influence of farm odour emissions.

Emission from slurry tanks were sampled using a floating sampling hood from Olfasense, designed for surface emission and then analysed using dynamic olfactometry.

Two samples were taken from an area close to the ventilators, from two locations of the pigsty.

\section{Mathematical modelling of odour dispersion}

Emission data were processed using mathematical modelling of dispersion with a package of programmes Aermod View. AERMOD View is a complete and powerful air dispersion modelling package which seamlessly incorporates the following popular U.S. EPA air dispersion models into one integrated interface: AERMOD, ISCST3 and ISCPRIME;

The package includes a meteorological data processor and a terrain processor.

Meteorological data were provided by the National Administration of the Meteorology and were treated with the dedicated processor AERMET. The data consisted in hourly averages of wind speed, wind direction, temperature, absolute pressure, cloud cover and humidity.

Terrain data were processed with the terrain processor AERMAP using SRTM 1 data with a resolution of $30 \mathrm{~m}$.

The unit is in the middle of the map, marked with a quadrilateral frame, same as the slurry tanks area. The three villages from nearby the farmwere marked with a red circle filled with lines. To process the data with the modelling software it is necessary to have an emission rate objectively calculated for each emission source, since the modelling software already have a high calculation uncertainty (8).

\section{Results and discussions}

Measurement results and emission rate calculation

Result of the measurements of odour emission and calculation of the emission rate are presented in Table 1.

First the homogeneity of the pollutants in the air was tested with an GrayWolf analyser with $\mathrm{NH}_{3}$ and $\mathrm{H}_{2} \mathrm{~S}$ electrochemical cells, indicating a very small variation close to all 6 ventilators. 
The emission rate was calculated taking in consideration that each pigsty has a ventilation system completely automated that is connected to an indoor air quality monitor that triggers the system according with the concentration of $\mathrm{CO}_{2}, \mathrm{NH}_{3}, \mathrm{H}_{2} \mathrm{~S}$ or temperature. The system is composed of 6 ventilators with a flow of $12000 \mathrm{~m}^{3} / \mathrm{h}\left(3.33 \mathrm{~m}^{3} / \mathrm{s}\right)$ each.

The calculation of the emission rate (column no. 7) was done using the concentration measured and the flow calculated using the data collected from the ventilation system.

For the slurry tanks the measurements were done only on Tank 1 and the values extrapolated to all tanks, because all of them had the same capacity of slurry with similar temperature and age. The odour emission factor corresponding to surface emission from tanks was $19 \mathrm{OU} / \mathrm{s} / \mathrm{m}^{2}$. Based on this factor and on the total area of the tanks, the odour emission was calculated using formula: $19 \mathrm{OU} / \mathrm{s} / \mathrm{m}^{2} \times 6 \times 2000 \mathrm{~m}^{2}=228000 \mathrm{OU} / \mathrm{s}$.

Table 1

RESULTS OF MEASUREMENTS AND EMISSION RATE CALCULATION

\begin{tabular}{|c|c|c|c|c|c|c|}
\hline Pisty no. & $\begin{array}{l}\text { Pig approx } \\
\text { weight } / \text { kg }\end{array}$ & $\begin{array}{c}\text { Odour average } \\
\text { concentration/ } \\
\text { OU/m } / \mathbf{m}^{3}\end{array}$ & No. of pigs & No. vent & Flow $\left(\mathbf{m}^{3} / \mathbf{s}\right)$ & $\begin{array}{c}\text { Emission rate } \\
\text { OU/s }\end{array}$ \\
\hline 1 & 60 & 1323 & 2750 & 4 & 13.32 & 17622.36 \\
\hline 2 & 60 & 1323 & 2652 & 4 & 13.32 & 17622.36 \\
\hline 3 & 60 & 1323 & 2739 & 4 & 13.32 & 17622.36 \\
\hline 4 & 60 & 1323 & 2855 & 4 & 13.32 & 17622.36 \\
\hline 5 & 70 & 1323 & 2734 & 5 & 16.65 & 22027.95 \\
\hline 6 & 70 & 1323 & 2729 & 5 & 16.65 & 22027.95 \\
\hline 7 & 70 & 1323 & 2705 & 5 & 16.65 & 22027.95 \\
\hline 8 & 70 & 1323 & 2807 & 5 & 16.65 & 22027.95 \\
\hline 9 & 80 & 1402 & 2749 & 5 & 16.65 & 23343.3 \\
\hline 10 & 80 & 1402 & 2733 & 5 & 16.65 & 23343.3 \\
\hline 11 & 80 & 1402 & 2666 & 5 & 16.65 & 23343.3 \\
\hline 12 & 80 & 1402 & 2729 & 5 & 16.65 & 23343.3 \\
\hline 13 & 40 & 492 & 2745 & 3 & 9.99 & 4915.08 \\
\hline 14 & 40 & 492 & 2731 & 3 & 9.99 & 4915.08 \\
\hline 15 & 40 & 492 & 2782 & 3 & 9.99 & 4915.08 \\
\hline 16 & 40 & 492 & 2766 & 3 & 9.99 & 4915.08 \\
\hline 17 & 30 & 492 & 2754 & 2 & 6.66 & 3276.72 \\
\hline 18 & 30 & 492 & 2781 & 2 & 6.66 & 3276.72 \\
\hline 19 & 30 & 492 & 2793 & 2 & 6.66 & 3276.72 \\
\hline 20 & 30 & 492 & 2791 & 2 & 6.66 & 3276.72 \\
\hline
\end{tabular}

Results were introduced in the modelling program by creating an individual point source with the corresponding emission rate for all 20 pigsties.

In case of the slurry tanks, because they positioned on a line, parallel with the farm, it was possible to be introduced as a single surface source of $12000 \mathrm{~m}^{2}$, with a similar position as original, and the corresponding odour emission factor.

Air dispersion modelling results

The result of the metheorological processing indicate thatthe predominant wind directions are $\mathrm{W}(25 \%)$ and E-SE (20\%) (Fig. 2). Low winds are very often $(0.5-2.1 \mathrm{~m} / \mathrm{s})$, covering appox. $67 \%$ of whole data with a total calm of $7.95 \%$ (Fig. 3).

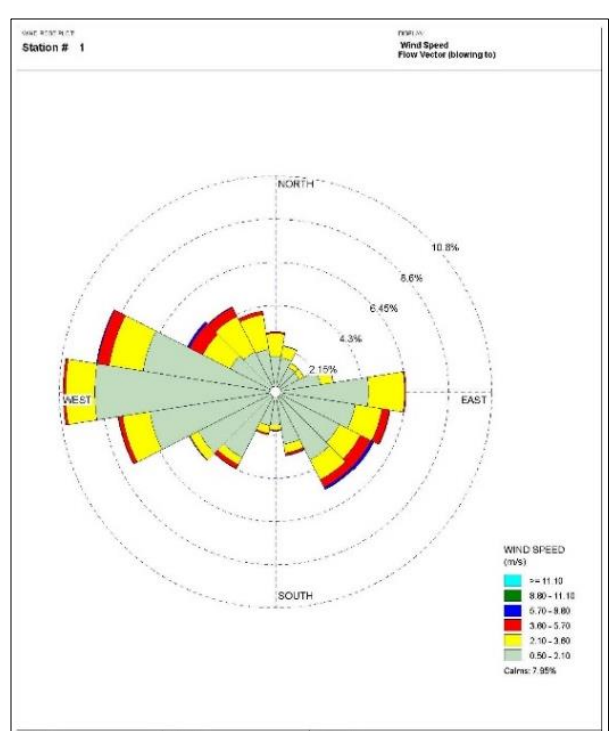

Fig. 2 Wind rose

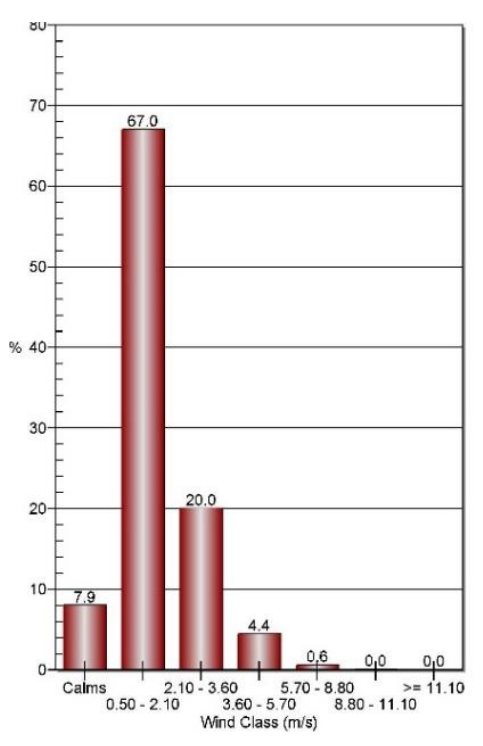

Fig. 3 Wind Class Frequency Distribution 
Results of the modelling indicate a strong impact on the settlements, with maximum levels of 100 to 300 OU in all three locations, and a maximum concentration of $1402 \mathrm{OU}$ around pigsties (Fig 4).

The modelling was done using the "highest value" function with a percentile of $100^{\text {th }}$, according with the Environmental Agency recommendations. The results cannot be interpreted as a constant pollution of the receptor with these concentrations, but rather the highest concentrations reached related to the meteorological data used and the monitored emissions estimated to the same level for the whole year.

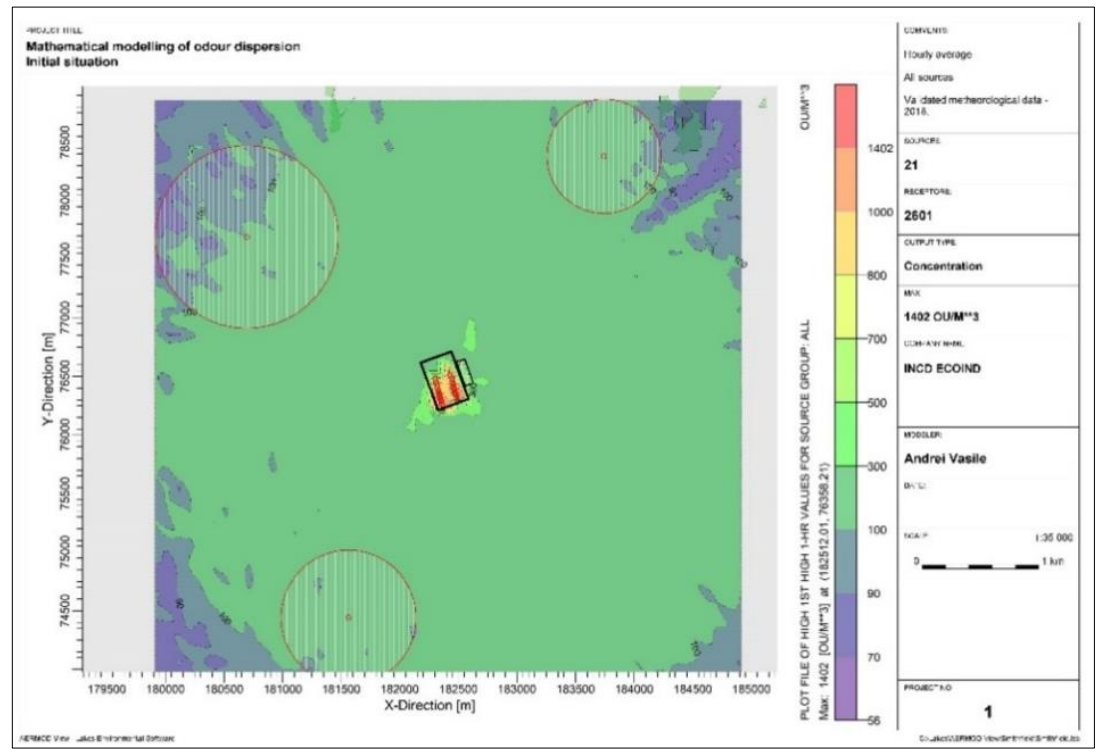

Fig. 4. Initial situation with all sources

To isolate the impact of the sources, a dispersion only with slurry tanks as an odour source was processed (Fig 5).

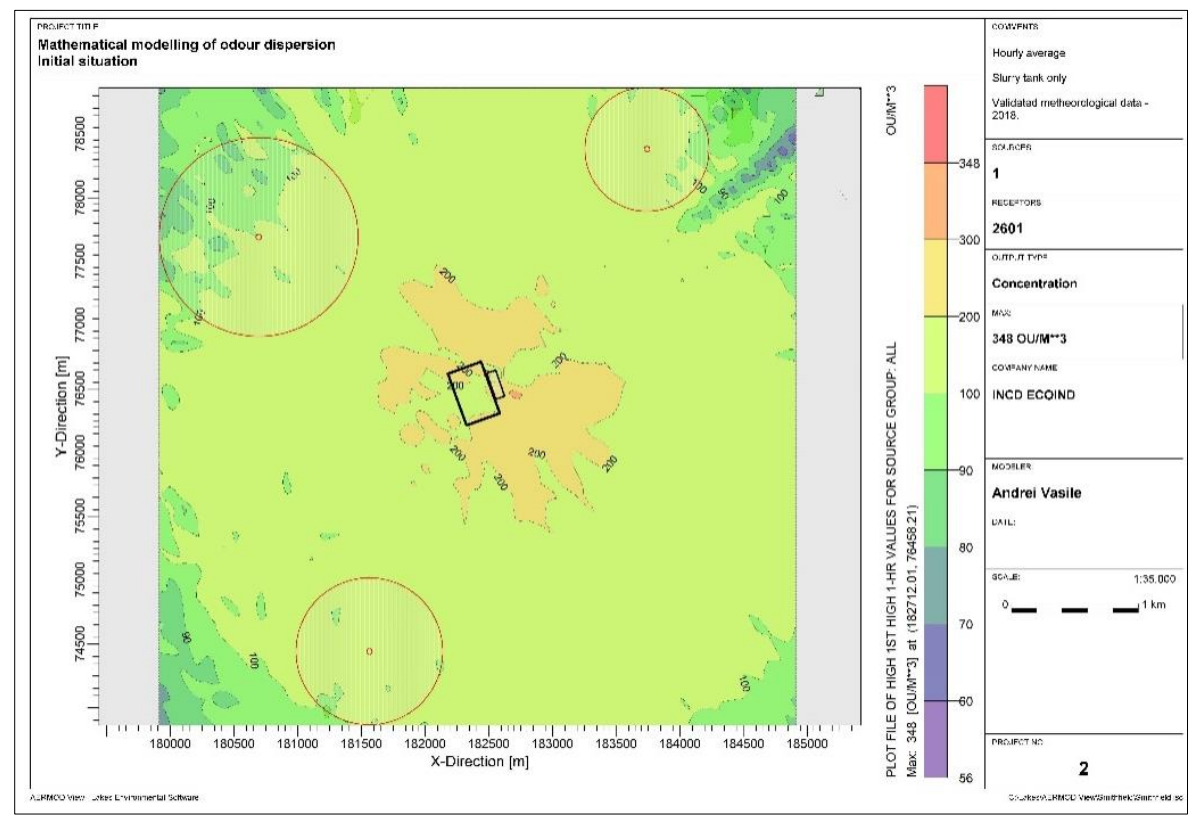

Fig.5 Initial situation only with slurry tanks

The results indicate the slurry tanks as a very important source of pollution, the concentration in the settlements are from 70 to $200 \mathrm{OU}$, and the maximum concentration measure around the slurry tanks is $345 \mathrm{OU}$.

Based on these results, an odour reducing plan was implemented and the farm started to treat the floor of the pigsties, the slurry transportation channels and the slurry tanks with products containing a combination of bacteria and enzymes able to reduce the Ammonia level and break down her sulphurous compounds in the slurry.

After the products reached the peak of the effect, all measurements were conducted again and the corresponding emission rates were calculated.

The concentrations measured decreased with $47 \%$ in the pigsties and $68 \%$ on the slurry tanks.

After rerunning of the modelling with all sources and the updated emission values it can be observed that the concentrations in the settlements suffered a decrease of approx. 60\%, from 100 to $300 \mathrm{OU}$ in the initial situation, to 33 to $100 \mathrm{OU}$ (Fig. 6). 


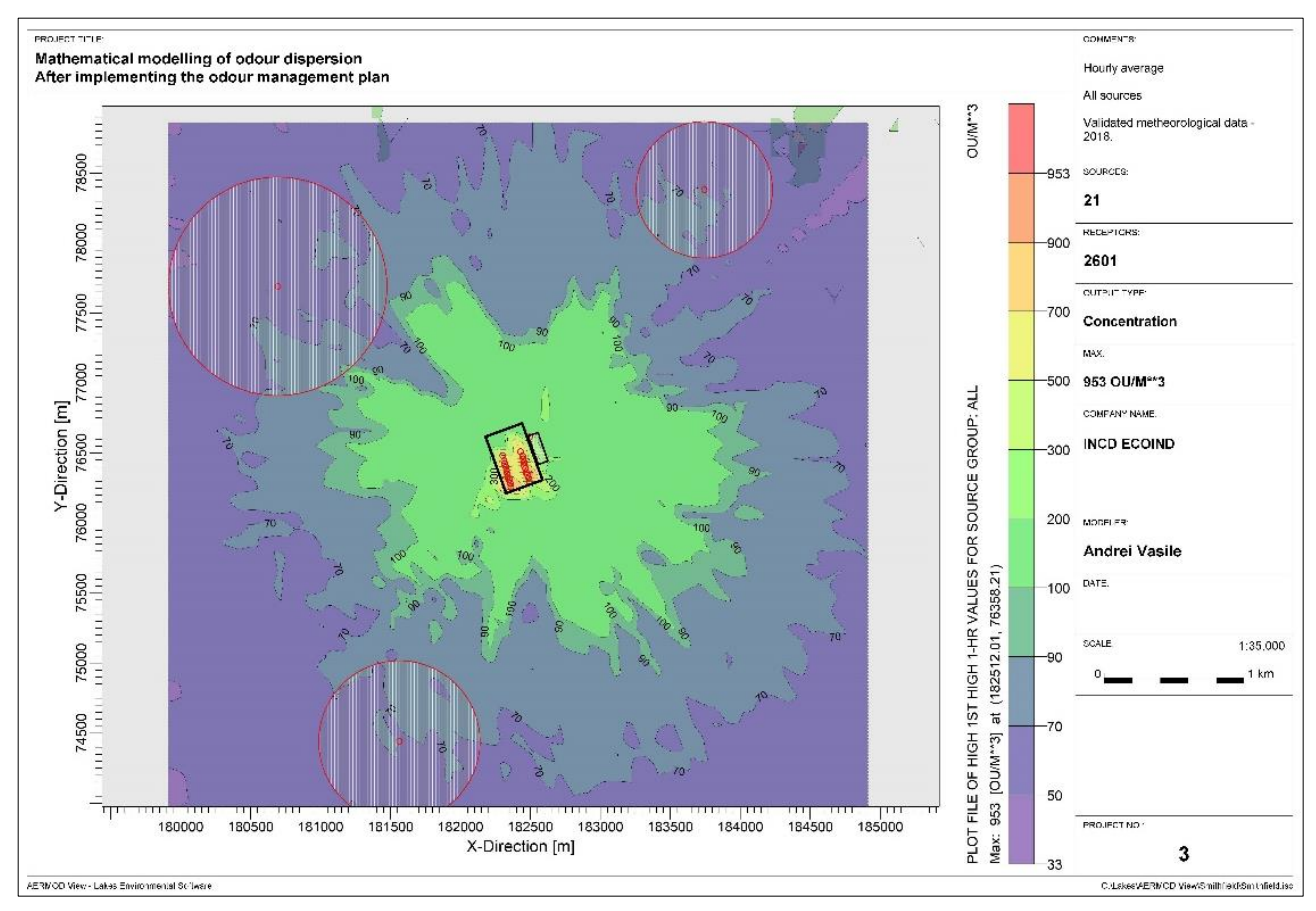

Fig. 6.Final situation with the emissions reduced

We can observe that the maximum concentration decreased with $67.9 \%$ from 1402 OU to $953 \mathrm{OU}$, meaning not only a decrease of the odour level, but also an increase in the quality of working conditions for the employees and a better environment for pigs. The quality of the slurry as an agricultural fertilizer increased and it is now possible to use the slurry for other agricultural applications, conducting to a lower quantity of stored slurry and lower emission.

Results of the evaluation of annoyance using FIDOL (Frequency, Intensity, Duration, Offensiveness and Location) factors indicate that almost all factors are negatively contributing to the overall annoyance: Frequency is very often; Intensity is very high; Duration is generally long, depending on wind direction/speed and the Offensiveness of this type of odour is also very high. The only positive factor is the Location since the farm has a long history and settlements was build closer and closer to it manly by former farm workers.

\section{Conclusions}

The study analysed the impact of odour emissions generated by a big pig farm on 3 nearby settlements to identify and apply a specific set of measures to reduce the level of pollution.

Odour measurements were done using dynamic olfactometry and the concentration in settlements was calculated using an air dispersion model. Result indicated a very high level of pollution in the settlements generated by the farm odour emissions. In order to reduce it, the experts of the farm applied a series of biological treatments on the floor of the pigsties, in the slurry transportation channels and in the slurry tanks. The products used were designed to reduce the Ammonia level, break down her sulphurous compounds in the slurry and increase the quality of the slurry as fertilizer, with the final target of reducing the odour emissions.

To verify the efficiency of the measures, new tests were done, including a new air dispersion using modelling. Results indicate that the concentrations in the closest settlements decreased with approx. $60 \%$, but the measures were not enough to reduce the levels of odours to a value acceptable at European level for pig farms, which is in most of the countries less than $10 \mathrm{OU} / \mathrm{m}^{3}$ at percentiles ranging from $98^{\text {th }}$ to $100^{\text {th }}$.

The studies on odour pollution are very recent in our country, mostly because it was not possible to measure the level of odour in Romania, before the inauguration of the first Laboratory for Odour Determination Using Dynamic Olfactometry. They will be continued as the demand is very high and it is necessary to create a base of knowledge for the future environmental national regulations.

Acknowledgements: This research was funded by "NUCLEU" Research Project, developed with the MCI support Project no 20N/2019; the authors would like to thank all those who contributed to this study.

\section{References}

1.*** 2017 best available techniques (BAT) reference document for the intensive rearing of poultry or pigs, EUR 28674 EN

2.LEE, M.H., KIM, K.H., JEON, B.H., JO, S.H., KIM, Y.H., KIM, B.W., CHO, S.B., HWANG, O.H., BHATTACHARYA, S.S., Waste Manage. (Oxford), 39, 2016, p.130.

3.DOMINGO, J.L., NADAL, M., Environ. Int., 35, no. 2, 2009, p. 382.

4.BUCUR, E., VASILE, A., PETRESCU, M., DANET, A., J. Environ. Prot. Ecol., 17, no. 1, 2016, p. 9.

5.BUCUR, E., DANET, A., Rev. Chim. (Bucharest), 67, no. 4, 2016, p. 621. 
6.PETRESCU, M., BUCUR, E., DIODIU, R., BRATU, M., SERBANESCU, A., BARBU, E.M., 20th International Symposium on The Environment and the Industry (SIMI), Bucharest, Romania, 2017, p. 213;

7.JUN ZHU, Agriculture, Ecosystems and Environment, 78, 2000, p. 93.

8.VASILE, A., DANCIULESCU, V., TANASE, G., KIM, L., DEDIU, V., Rev. Chim. (Bucharest), 68, no. 8, 2016 , p.1749.

Manuscript received: 31.07 .2019 